Article

\title{
Genome-Wide Identification and Expression Profiles of Late Embryogenesis-Abundant (LEA) Genes during Grain Maturation in Wheat (Triticum aestivum L.)
}

\author{
Datong Liu ${ }^{1}{ }^{\circledR}$, Jing Sun ${ }^{2}$, Dongmei Zhu ${ }^{1}$, Guofeng Lyu ${ }^{1}$, Chunmei Zhang ${ }^{1}$, Jian Liu ${ }^{1}$, \\ Hui Wang ${ }^{1}$, Xiao Zhang ${ }^{1}$ and Derong Gao ${ }^{1, *}$ \\ 1 Key Laboratory of Wheat Biology and Genetic Improvement for Low \& Middle Yangtze Valley, Ministry of \\ Agriculture/Lixiahe Agricultural Institute of Jiangsu Province, Yangzhou 225007, China; ldt@wheat.org.cn \\ 2 Yangzhou University, Yangzhou 225009, China \\ * Correspondence: gdr@wheat.org.cn; Tel.: +86-051487308863
}

Received: 21 July 2019; Accepted: 6 September 2019; Published: 10 September 2019

check for updates

\begin{abstract}
Late embryogenesis-abundant (LEA) genes play important roles in plant growth and development, especially the cellular dehydration tolerance during seed maturation. In order to comprehensively understand the roles of LEA family members in wheat, we carried out a series of analyses based on the latest genome sequence of the bread wheat Chinese Spring. 121 Triticum aestivum L. LEA (TaLEA) genes, classified as 8 groups, were identified and characterized. TaLEA genes are distributed in all chromosomes, most of them with a low number of introns $(\leq 3)$. Expression profiles showed that most TaLEA genes expressed specifically in grains. By qRT-PCR analysis, we confirmed that 12 genes among them showed high expression levels during late stage grain maturation in two spring wheat cultivars, Yangmai16 and Yangmai15. For most genes, the peak of expression appeared earlier in Yangmai16. Statistical analysis indicated that expression level of 8 genes in Yangmai 16 were significantly higher than Yangmai 15 at 25 days after anthesis. Taken together, our results provide more knowledge for future functional analysis and potential utilization of TaLEA genes in wheat breeding.
\end{abstract}

Keywords: late embryogenesis-abundant gene; wheat (Triticum aestivum L.); grain maturation; genome-wide identification

\section{Introduction}

The dehydration process of embryos during grain maturation is the terminal event of seed development, correlating with the acquisition of desiccation tolerance and with the specific induction of highly abundant hydrophilic proteins described as Late Embryogenesis Abundant (LEA) [1,2]. This process indicates the "switch" of seed transformation from development to germination, acting as an adaptability strategy of angiosperm to ensure the survival of seeds during storage or the environmental stress of long-term evolution [3,4]. Seeds are classified as orthodox and recalcitrant based on their storage behavior and desiccation tolerance in the drying process [5]. Orthodox seeds undergo mature dehydration on the maternal plants. Their water content is usually low and can be further dried to 1 to $5 \%$ moisture without damage $[4,6]$.

LEA was first isolated from cotyledons of cotton at the late embryonic development stage [7]. In the following 30 years, LEA proteins have been detected in a variety of higher plant development seeds [8-13]. The LEA family is usually composed of multiple members in plants. Previous study identified at least 13 and 34 LEA homologous genes in maize [14] and rice, respectively [15]. With the development of genome-wide sequencing technology, the LEA gene family has been further 
elucidated in many other species, such as Solanum lycopersicum (27 LEA genes) [16], Dendrobium officinale (Orchidaceae) (17) [17], Brassica mapus (108) [18], Amaranth (105) [19], and Solanum Tuberosum (74) [13]. Furthermore, LEA genes are not unique to plants. They have been also identified in fungi, bacteria and animals [20].

LEA proteins have small molecular weights from 10 to $30 \mathrm{kDa}$. They are enriched in glycine and other hydrophilic amino acids, resulting in high hydrophilicity and thermal stability [21]. LEA proteins consist of a non-periodic linear and facultative $\alpha$-helix which formed the main hydrophobic interaction between monomers without thermodynamically dominant state $[8,22]$. According to the similarity, LEA family is generally divided into 8 groups, namely LEA1, LEA2, LEA3, LEA4, LEA5, LEA6, dehydrin and SMP (seed maturation protein) [23]. Recently, ASR proteins (abscisic stress ripening) were classified as LEA7 group [24,25], extending LEA family to 9 groups. The division of family members is not consistent in different species [26]. While the sequence conservation implies their conserved role in desiccation tolerance [27].

Moreover, LEA proteins were reported to be widely involved in plant stress response in Arabidopsis, tobacco, grape, and other species [28]. In monocotyledons such as maize, wheat and rice, LEA expression can be induced by varieties of abiotic stresses to improve plant tolerance [29-31], which is beyond the scope of this article.

Wheat, as an important staple crop in the world, is becoming the focus of global food security issues [32,33]. In China, due to changes of climate and cultivation methods, new requirements for early maturing traits and dehydration characteristics of winter wheat have been put forward recently [34,35]. The moisture content of wheat seeds, like orthodox seeds, decline up to $40 \%$ quickly after physiological ripening. The speed of grain dehydration affects the desiccation tolerance and is highly related to the harvest time after maturity. Rapid dehydration after maturity is able to avoid the bad meteorological conditions in late stages of seed maturation, reduce the occurrence of pre-harvest sprouting, and shorten the cost of drying after harvest.

Wheat is an allohexaploid species with a large and complex genome consisting of three closely related sub genomes $(\mathrm{A}, \mathrm{B}$, and $\mathrm{D})$. The continuous improvement and release of genomic data promoted the identification and analysis of wheat genes genome-widely [36-42]. The identification and use of the elite gene resource may help us improve the stress tolerance of wheat and solve the problems caused by changing global climate and food security status [42].

In this study, we systematically characterized the LEA genes in wheat based on the latest genome sequences. The genome composition, phylogeny, conserved motifs, chromosome locations, and the expression pattern of TaLEA proteins were systematically analyzed. These results will not only help us to reveal the molecular mechanism of mature dehydration in wheat and other cereal crops, but also provide a theoretical basis for their application to promote crop variety improvement.

\section{Materials and Methods}

\subsection{Identification and Phylogenetic Analysis of Late Embryogenesis-Abundant (LEA) Genes in Wheat Genomes}

The nucleotide and protein sequence in the whole-genome of T. aestivum was downloaded from the wheat genome URGI database (https://wheat-urgi.versailles.inra.fr/Seq-Repository). These sequences were first used to construct a local protein database with which to search against known LEA protein sequences collected from A. thaliana (51) [9] and O. sativa (34) [15], through a local protein basic local alignment search (BLASTP) program (https://blast.ncbi.nlm.nih.gov) with an E-value cut-off $<10^{-10}$ and an identity of $50 \%$ as the threshold. The Hidden Markov Model (HMM) which was constructed using HMMER 3.0 program was used to search all the encoding protein sequences of wheat to find all predicted LEA family members. A self-blast of these sequences was performed by comparing of HMMER and BLAST hits to remove the redundancy, and no alternative splice variants were considered. The aligned sequences were then used as candidate LEA family sequences. The obtained candidate sequences were subjected to domain annotation of the target sequence using the 
software PfamScan and Pfam A databases, and the sequences containing the complete LEA-1 (Pfam ID PF03760.14), LEA-2 (PF03168.12), LEA-3 (PF03242.12), LEA-4 (PF02987.15), LEA-5 (PF00477.16), LEA-6 (PF10714.8), Dehydrin (PF00257.18), and SMP (PF04927.11) domains were identified as the final wheat LEA family sequences. The identified wheat LEA proteins were termed according to the subfamily it belongs and the order of gene ID. The biochemical parameters such as theoretical isoelectric point (PI), molecular weight (MW), amino acid number, instability, and hydrophilicity of the obtained proteins were calculated by the ProtParam (http://web.expasy.org/protparam/). To investigate the evolutionary relationships among these TaLEA genes, multiple sequence alignment was performed using MAFFT (Multiple Alignment using Fast Fourier Transform: http://mafft.cbrc.jp/alignment/software/) with the default parameters. A tree was constructed based on the full-length protein sequences using the Neighbor-Joining (NJ) method with Partial deletion and p-distance model, and a Bootstrap test of 1000 replicates for internal branch reliability. Another two phylogenetic trees for LEA protein family of T. aestivum, O. sativa, and $A$. thaliana were generated using Maximum-Likehood [ML, by FastTree (an open-source software developed by Morgan N. Price in Adam Arkin's group at Lawrence Berkeley National Lab, Berkeley, USA) with default parameters] and Maximum-Parsimony (MP, by MEGA7.0 software [43] with the Max No. of Trees to Retain as 100) method to better understand the evolution of LEA genes.

\subsection{Structural Characterisation of Wheat LEA}

The exon-intron structures of the TaLEA family genes were determined based on alignments of their coding sequences with the corresponding genomic sequences, and a diagram was obtained using GSDS (Gene structure display server: http://gsds.cbi.pku.edu.cn/). To better understand the similarity and diversity of protein motifs, MEME (Multiple Expectation Maximization for Motif Elicitation: http://meme.nbcr.net/meme) was used to identify the conserved motif structures encoded by each group of TaLEA family genes. The parameters as follow: optimum motif widths of 6-50 residues and a maximum of 15 motifs. The schematic diagram of the amino acid motifs for each TaLEA gene was drawn accordingly.

\subsection{Distribution of LEA Genes on Wheat Chromosomes}

TaLEA were mapped on wheat chromosomes according to the positional information of the TaLEA genes from the wheat genome annotation datebase, and the chromosome physical location map was displayed using MG2C (Map Gene 2 Chromosome V2: http://mg2c.iask.in/mg2c_v2.0/).

\subsection{Expression Profile Analysis of Wheat LEA Genes}

The publicly available wheat RNA-Seq datasets used for generating gene expression levels were downloaded from the Wheat Expression Browser (http://www.wheat-expression.com), then used to analyze the expression profiles of the identified TaLEA genes. These data are from the studies of developmental time-course of common hexaploid wheat variety Azhurnaya and Chinese Spring. The results were summarized according to high expression level tissues as grains, roots, leaves/shoots, and spikes. The original TPM (transcripts per kilobase million) of each gene plus 0.0001 to prevent an expression value of ' 0 '. The heat map was drawn in $\log _{10}(\mathrm{tpm}+0.0001)$-transformed expression values according to the standardization. Genes highly expressed in the grain were selected for qRT-PCR detection.

\subsection{Plant Materials, Growth Conditions, and Sampling}

Based on many years production experience and research, Yangmai16 had a faster grain filling speed, earlier maturity compared with Yangmai15 [35]. Therefore, these two spring wheat varieties Yangmai16 and Yangmai15, which were bred by the author's unit, were planted and cultivated under the same condition. At the flowering stage, two individual florets at the base of the center ears were marked with a marker pen and the plants were tagged with anthesis dates. Wheat grains 
were sampled at 10, 15, 20, 25, 30, and 35 DAA (days after anthesis) for extraction of total RNA and further determination.

\subsection{Quantitative Real-Time Polymerase Chain Reaction Analysis of TaLEA Proteins}

In order to identify the expression profile of TaLEA gene in different wheat cultivars, and to explain the relationship between the LEA protein and maturity, as well as the grain production, high expression level LEA genes were collected for quantitative real-time polymerase chain reaction (qRT-PCR) analysis. Total RNA was extracted from the seeds by Trizol reagent (Biotech, Shanghai), and the first strand of cDNA was synthesized using Transcriptor First Strand cDNA Synthesis Kit (Roche, Penzberg, Germany). The wheat gene Actin was used as an internal reference, and the selected 12 TaLEA genes, including TaDehydrin-1, TaDehydrin-3, TaDehydrin-5, TaDehydrin-7, TaLEA1-1, TaLEA1-3, TaLEA4-13, TaLEA5-1, TaLEA5-3, TaLEA5-4, TaSMP-1 and TaSMP-2, were subjected to qRT-PCR using a fluorescence quantitative reagent Ultra SYBR Mixture (Kang Wei Century, Beijing) on a Roch Light-Cycler 480 fluorescence quantitative PCR machine (Roche, Penzberg, Germany); three independent biological replicates. The primer sequences used are listed in Table S1.

\subsection{Determination of the Dry Weight and Moisture Content of Grains}

Sampled grains were used for measurements of grain dry weight and moisture content. The fresh grains then dried at $70{ }^{\circ} \mathrm{C}$ to constant weight were weighed for the fresh weight $\left(W_{F}\right)$ and dry weight $\left(W_{D}\right)$. Moisture content of grains was calculated by $\left(W_{F}-W_{D}\right) / W_{F} \times 100 \%$.

The processes of grain filling were fitted by Logistic' equation as described by [44]:

$$
f(x)=a /(1+b \times \exp (-c \times x))
$$

The dehydration progress was fitted by Gompertz equation as described by [45]:

$$
f(x)=a \times \exp (-\exp (-b \times(x-c)))
$$

\section{Results}

\subsection{Genome-Wide Identification and Phylogenetic Analysis of Wheat LEA Genes}

Based on genome-wide blast, a total of 121 non-redundant LEA homologous containing the complete LEA, Dehydrin, and SMP domains were identified from the hexaploid wheat genome, which were considered as the putative wheat $L E A$ genes. By phylogenetic analysis, these 121 genes were divided into 8 groups (groups LEA1-LEA6, Dehydrin, and SMP) (Table 1). The largest group Dehydrin contains 47 members, while the smallest groups $L E A 3$ and $L E A 6$ have only two members. Groups LEA1, LEA2, LEA4, LEA5, and SMP contain 19, 15, 15, 4, and 17 genes, respectively.

\begin{tabular}{|c|c|c|c|c|c|c|c|}
\hline Gene_Name & Gene_ID & $\begin{array}{l}\text { Amino Acid } \\
\text { Number }\end{array}$ & MW & pI & $\begin{array}{l}\text { Instability } \\
\text { Index }\end{array}$ & $\begin{array}{l}\text { Aliphatic } \\
\text { Index }\end{array}$ & GRAVY \\
\hline TaDehydrin-1 & TraesCS3A02G254600 & 213 & $21,831.76$ & 6.25 & 35.63 & 46.76 & -0.83 \\
\hline TaDehydrin-10 & TraesCS5A02G369800 & 143 & $14,570.81$ & 8 & 34.57 & 36.36 & -1.151 \\
\hline TaDehydrin-11 & TraesCS5A02G369900 & 140 & $14,240.47$ & 8.01 & 38 & 39.86 & -1.083 \\
\hline TaDehydrin-12 & TraesCS5A02G424800 & 149 & $15,217.65$ & 9.33 & 25.94 & 32.21 & -1.087 \\
\hline TaDehydrin-13 & TraesCS5B02G372100 & 143 & $14,429.64$ & 8 & 34.24 & 35.66 & -1.118 \\
\hline TaDehydrin-14 & TraesCS5B02G372200 & 138 & $14,218.46$ & 8.01 & 38.03 & 38.99 & -1.104 \\
\hline TaDehydrin-15 & TraesCS5B02G426700 & 150 & $15,176.65$ & 9.52 & 31.65 & 34.6 & -1.062 \\
\hline TaDehydrin-16 & TraesCS5B02G426800 & 150 & $15,221.65$ & 9.36 & 24.14 & 32 & -1.063 \\
\hline TaDehydrin-17 & TraesCS5D02G379200 & 143 & $14,515.73$ & 7.11 & 33.97 & 36.99 & -1.123 \\
\hline TaDehydrin-18 & TraesCS5D02G379300 & 133 & $13,930.2$ & 8.81 & 40.1 & 38.95 & -1.189 \\
\hline TaDehydrin-19 & TraesCS5D02G433200 & 152 & $15,345.79$ & 9.52 & 27.66 & 32.24 & -1.05 \\
\hline
\end{tabular}

Table 1. Description of Late Embryogenesis Abundant (LEA) genes identified from the wheat genome. 
Table 1. Cont

\begin{tabular}{|c|c|c|c|c|c|c|c|}
\hline Gene_Name & Gene_ID & $\begin{array}{c}\text { Amino Acid } \\
\text { Number }\end{array}$ & MW & pI & $\begin{array}{l}\text { Instability } \\
\text { Index }\end{array}$ & $\begin{array}{c}\text { Aliphatic } \\
\text { Index }\end{array}$ & GRAVY \\
\hline TaDehydrin-2 & TraesCS3A02G396200 & 275 & $27,016.77$ & 9.6 & 26.32 & 37.13 & -0.775 \\
\hline TaDehydrin-20 & TraesCS5D02G433300 & 154 & $15,587.09$ & 9.52 & 25.9 & 31.17 & -1.024 \\
\hline TaDehydrin-21 & TraesCS5D02G519300LC & 266 & $28,166.53$ & 9.76 & 46.85 & 52.93 & -0.803 \\
\hline TaDehydrin-22 & TraesCS6A02G059800 & 153 & $15,511.87$ & 8.84 & 37 & 39.08 & -1.041 \\
\hline TaDehydrin-23 & TraesCS6A02G253300 & 268 & $28,823.05$ & 5.25 & 56.43 & 63.73 & -0.997 \\
\hline TaDehydrin-24 & TraesCS6A02G350500 & 221 & $22,048.66$ & 9.05 & 7.59 & 23.48 & -1.071 \\
\hline TaDehydrin-25 & TraesCS6A02G350600 & 162 & $16,284.68$ & 9.22 & 17.14 & 38.02 & -0.994 \\
\hline TaDehydrin-26 & TraesCS6A02G350700 & 152 & $15,522.71$ & 7.17 & 27.53 & 31.51 & -1.176 \\
\hline TaDehydrin-27 & TraesCS6A02G350800 & 143 & $14,815.21$ & 9.22 & 37.6 & 36.36 & -1.012 \\
\hline TaDehydrin-28 & TraesCS6A02G350900 & 190 & $20,142.87$ & 10.74 & 50.46 & 35.63 & -1.274 \\
\hline TaDehydrin-29 & TraesCS6B02G273400 & 259 & $27,973.07$ & 5.2 & 57.39 & 62.93 & -1.054 \\
\hline TaDehydrin-3 & TraesCS3B02G286600 & 217 & $22,297.38$ & 6.87 & 35.47 & 47.7 & -0.856 \\
\hline TaDehydrin-30 & TraesCS6B02G383200 & 405 & $40,293.09$ & 6.83 & -0.26 & 29.98 & -1.064 \\
\hline TaDehydrin-31 & TraesCS6B02G383500 & 231 & $23,229.05$ & 9.22 & 2.83 & 23.25 & -1.074 \\
\hline TaDehydrin-32 & TraesCS6B02G383600 & 158 & $15,838.17$ & 9.13 & 23.2 & 34.11 & -1.041 \\
\hline TaDehydrin-33 & TraesCS6B02G383800 & 166 & $16,704.04$ & 8.05 & 17.71 & 33.01 & -1.054 \\
\hline TaDehydrin-34 & TraesCS6B02G695700LC & 162 & $16,127.46$ & 9.19 & 13.99 & 35 & -0.983 \\
\hline TaDehydrin-35 & TraesCS6B02G695800LC & 162 & $16,127.46$ & 9.19 & 13.99 & 35 & -0.983 \\
\hline TaDehydrin-36 & TraesCS6B02G695900LC & 162 & $16,097.44$ & 9.19 & 14.98 & 35.62 & -0.968 \\
\hline TaDehydrin-37 & TraesCS6D02G234700 & 262 & $28,155.2$ & 5.19 & 57.34 & 61.83 & -1.051 \\
\hline TaDehydrin-38 & TraesCS6D02G332900 & 231 & $23,020.75$ & 9.05 & 6.9 & 24.16 & -1.028 \\
\hline TaDehydrin-39 & TraesCS6D02G333000 & 162 & $16,195.51$ & 8.05 & 14.92 & 33.21 & -1.019 \\
\hline TaDehydrin-4 & TraesCS3B02G428200 & 274 & $27,193.96$ & 9.74 & 24.64 & 34.34 & -0.859 \\
\hline TaDehydrin-40 & TraesCS6D02G333100 & 144 & $14,512.72$ & 9.19 & 15.79 & 33.96 & -1.076 \\
\hline TaDehydrin- 41 & TraesCS6D02G333200 & 155 & 15,729 & 8.83 & 26.81 & 34.06 & -1.125 \\
\hline TaDehydrin-42 & TraesCS6D02G333300 & 160 & $16,255.59$ & 8.07 & 21.61 & 39.81 & -1.05 \\
\hline TaDehydrin-43 & TraesCS6D02G333600 & 167 & $16,712.02$ & 7.17 & 14.3 & 31.08 & -1.062 \\
\hline TaDehydrin-44 & TraesCSU02G086200 & 151 & $15,288.66$ & 9.1 & 38.15 & 42.19 & -1.011 \\
\hline TaDehydrin-45 & TraesCSU02G122200 & 149 & $14,855.02$ & 6.86 & 33.61 & 40.13 & -0.947 \\
\hline TaDehydrin-46 & TraesCSU02G564500LC & 130 & $12,865.8$ & 9.05 & 25.25 & 32.38 & -0.968 \\
\hline TaDehydrin-47 & TraesCSU02G656800LC & 130 & $12,865.8$ & 9.05 & 25.25 & 32.38 & -0.968 \\
\hline TaDehydrin-5 & TraesCS3D02G255500 & 215 & $22,243.3$ & 6.63 & 37.53 & 44.51 & -0.912 \\
\hline TaDehydrin-6 & TraesCS3D02G390200 & 275 & $27,156.85$ & 9.7 & 23.91 & 34.58 & -0.855 \\
\hline TaDehydrin-7 & TraesCS4A02G250900 & 455 & $43,740.8$ & 8.84 & -6.02 & 31.38 & -0.779 \\
\hline TaDehydrin-8 & TraesCS4B02G064200 & 457 & $43,891.98$ & 8.84 & -3.84 & 32.74 & -0.741 \\
\hline TaDehydrin-9 & TraesCS4D02G063100 & 430 & $41,223.14$ & 9.04 & 0.85 & 31.65 & -0.773 \\
\hline TaLEA1-1 & TraesCS2A02G449700 & 110 & $11,589.91$ & 9.4 & 32.94 & 39.45 & -1.056 \\
\hline TaLEA1-10 & TraesCS5D02G177300 & 146 & $14,589.98$ & 7.11 & 25.53 & 57.81 & -0.588 \\
\hline TaLEA1-11 & TraesCS6B02G244900 & 102 & $10,650.63$ & 8.06 & 34.58 & 42.55 & -1.089 \\
\hline TaLEA1-12 & TraesCS7A02G030100 & 131 & $13,910.81$ & 9.87 & 39.53 & 54.66 & -0.852 \\
\hline TaLEA1-13 & TraesCS7A02G030300 & 115 & $12,294.95$ & 9.84 & 38.36 & 58 & -0.886 \\
\hline TaLEA1-14 & TraesCS7A02G042500 & 175 & $19,508.1$ & 10.39 & 47.89 & 52.23 & -1.061 \\
\hline TaLEA1-15 & TraesCS7A02G439200 & 147 & 14,483 & 9.13 & 30.34 & 57.48 & -0.453 \\
\hline TaLEA1-16 & TraesCS7B02G337800 & 147 & $14,522.94$ & 8.93 & 30.4 & 51.5 & -0.555 \\
\hline TaLEA1-17 & TraesCS7D02G026300 & 119 & $12,561.2$ & 9.84 & 33.94 & 56.13 & -0.845 \\
\hline TaLEA1-18 & TraesCS7D02G026400 & 115 & $12,306.88$ & 9.94 & 29.52 & 52.96 & -0.95 \\
\hline TaLEA1-19 & TraesCS7D02G428800 & 169 & $16,768.61$ & 9.56 & 24.28 & 55.86 & -0.442 \\
\hline TaLEA1-2 & TraesCS2A02G449800 & 110 & $11,406.59$ & 9.19 & 15.59 & 36.82 & -1.047 \\
\hline TaLEA1-3 & TraesCS2B02G471500 & 110 & $11,481.72$ & 8.69 & 28.51 & 39.45 & -0.993 \\
\hline TaLEA1-4 & TraesCS2B02G471600 & 120 & $12,363.79$ & 9.58 & 25.19 & 37.83 & -0.96 \\
\hline TaLEA1-5 & TraesCS2D02G449200 & 226 & $24,041.95$ & 10.1 & 51.53 & 45.66 & -0.828 \\
\hline TaLEA1-6 & TraesCS2D02G449300 & 116 & $12,059.47$ & 9.58 & 21.73 & 40.78 & -0.975 \\
\hline TaLEA1-7 & TraesCS4A02G459700 & 169 & $18,344.61$ & 10.03 & 45.86 & 55.15 & -0.931 \\
\hline TaLEA1-8 & TraesCS5A02G172800 & 146 & $14,712.07$ & 6.71 & 25.02 & 53.15 & -0.634 \\
\hline TaLEA1-9 & TraesCS5B02G170200 & 143 & $14,466.79$ & 6.65 & 24.27 & 54.34 & -0.645 \\
\hline TaLEA2-1 & TraesCS1A02G423800 & 163 & $17,826.52$ & 5.03 & 14.94 & 89.75 & -0.069 \\
\hline TaLEA2-10 & TraesCS3D02G091400 & 305 & $33,630.14$ & 4.65 & 28.86 & 92.98 & -0.329 \\
\hline TaLEA2-11 & TraesCS3D02G158600 & 151 & $16,272.66$ & 4.78 & 14.24 & 93.58 & -0.068 \\
\hline TaLEA2-12 & TraesCS3D02G227800 & 181 & $19,544.98$ & 4.29 & 26.07 & 80.17 & -0.173 \\
\hline TaLEA2-13 & TraesCS4A02G343300 & 333 & $36,961.06$ & 5.09 & 23.57 & 90.66 & -0.393 \\
\hline TaLEA2-14 & TraesCS5B02G531400 & 361 & $40,184.79$ & 4.96 & 28.8 & 95.76 & -0.288 \\
\hline TaLEA2-15 & TraesCS5D02G529700 & 326 & $36,210.08$ & 4.9 & 28.44 & 91.13 & -0.406 \\
\hline TaLEA2-2 & TraesCS1B02G455900 & 163 & $17,748.48$ & 5.17 & 17.63 & 92.76 & -0.022 \\
\hline TaLEA2-3 & TraesCS1D02G432400 & 163 & $17,808.55$ & 5.05 & 15.34 & 90.98 & -0.037 \\
\hline TaLEA2-4 & TraesCS3A02G091500 & 305 & $33,629.19$ & 4.65 & 24.8 & 94.89 & -0.297 \\
\hline TaLEA2-5 & TraesCS3A02G150800 & 151 & $16,254.62$ & 4.78 & 11.33 & 96.16 & -0.055 \\
\hline TaLEA2-6 & TraesCS3A02G225600 & 186 & $19,778.21$ & 4.37 & 28.98 & 76.45 & -0.165 \\
\hline TaLEA2-7 & TraesCS3B02G106700 & 305 & $33,625.18$ & 4.68 & 26.92 & 92.66 & -0.343 \\
\hline TaLEA2-8 & TraesCS3B02G240900LC & 162 & $17,614.16$ & 5.68 & 23.58 & 90.25 & -0.199 \\
\hline TaLEA2-9 & TraesCS3B02G255100 & 181 & $19,458.89$ & 4.33 & 26.15 & 79.12 & -0.169 \\
\hline TaLEA3-1 & TraesCS1B02G243600 & 115 & $12,671.65$ & 9.18 & 54.99 & 73.91 & -0.42 \\
\hline TaLEA3-2 & TraesCS7D02G389300 & 99 & $10,643.23$ & 10.11 & 52.88 & 76.26 & -0.167 \\
\hline
\end{tabular}


Table 1. Cont.

\begin{tabular}{|c|c|c|c|c|c|c|c|}
\hline Gene_Name & Gene_ID & $\begin{array}{c}\text { Amino Acid } \\
\text { Number }\end{array}$ & MW & pI & $\begin{array}{l}\text { Instability } \\
\text { Index }\end{array}$ & $\begin{array}{l}\text { Aliphatic } \\
\text { Index }\end{array}$ & GRAVY \\
\hline TaLEA4-1 & TraesCS1A02G364000 & 224 & $23,196.17$ & 8.81 & 22.88 & 37.46 & -1.118 \\
\hline TaLEA4-10 & TraesCS1D02G369800 & 214 & $21,965.87$ & 8.89 & 8.45 & 43.74 & -0.95 \\
\hline TaLEA4-11 & TraesCS3A02G188700 & 396 & $42,151.23$ & 5.06 & 40.57 & 45.88 & -0.962 \\
\hline TaLEA4-12 & TraesCS3D02G192100 & 407 & $43,198.53$ & 5.42 & 36.92 & 43 & -0.963 \\
\hline TaLEA4-13 & TraesCS4A02G129100 & 351 & $37,340.93$ & 6.5 & 20.4 & 47.04 & -1.007 \\
\hline TaLEA4-14 & TraesCS4B02G175600 & 363 & $38,561.24$ & 6.7 & 18.15 & 46.86 & -1.031 \\
\hline TaLEA4-15 & TraesCS4D02G177500 & 352 & $37,457.1$ & 6.44 & 20.76 & 49.12 & -0.97 \\
\hline TaLEA4-2 & TraesCS1A02G364100 & 163 & $17,097.7$ & 9.16 & 48.51 & 41.66 & -1.045 \\
\hline TaLEA4-3 & TraesCS1B02G381200 & 212 & $21,896.87$ & 9.02 & 21.71 & 36.75 & -1.096 \\
\hline TaLEA4-4 & TraesCS1B02G381400 & 178 & $18,146.72$ & 8.63 & 23.16 & 42.64 & -0.954 \\
\hline TaLEA4-5 & TraesCS1B02G381500 & 169 & 17,528 & 5.95 & 25.29 & 41.95 & -1.009 \\
\hline TaLEA4-6 & TraesCS1D02G369200 & 220 & $22,708.72$ & 9 & 21.62 & 36.82 & -1.108 \\
\hline TaLEA4-7 & TraesCS1D02G369300 & 163 & $16,930.39$ & 6.62 & 26.37 & 39.26 & -1.026 \\
\hline TaLEA4-8 & TraesCS1D02G369400 & 180 & $18,788.43$ & 5.99 & 28.19 & 40.5 & -1.046 \\
\hline TaLEA4-9 & TraesCS1D02G369500 & 180 & $18,740.37$ & 5.99 & 23.35 & 42.67 & -1.029 \\
\hline TaLEA5-1 & TraesCS1B02G237400 & 153 & $16,878.38$ & 5.57 & 37.06 & 33.2 & -1.539 \\
\hline TaLEA5-2 & TraesCS1B02G436600LC & 113 & $12,029.24$ & 5.53 & 41.95 & 51.06 & -0.962 \\
\hline TaLEA5-3 & TraesCS1D02G225800 & 153 & $16,771.27$ & 5.47 & 39.18 & 33.2 & -1.503 \\
\hline TaLEA5-4 & TraesCS3B02G166400 & 124 & $13,694.2$ & 5.17 & 54.16 & 61.45 & -1.308 \\
\hline TaLEA6-1 & TraesCS5A02G258900 & 121 & $12,844.87$ & 5.44 & 44.66 & 51.74 & -1.065 \\
\hline TaLEA6-2 & TraesCS5B02G257700 & 118 & $12,534.6$ & 5.67 & 42.9 & 48.9 & -1.044 \\
\hline TaSMP-1 & TraesCS4A02G030600 & 272 & $27,106.72$ & 4.72 & 35.79 & 70.59 & -0.336 \\
\hline TaSMP-10 & TraesCS5B02G390600 & 266 & $27,101.21$ & 5.15 & 38.24 & 77.56 & -0.316 \\
\hline TaSMP-11 & TraesCS5B02G390800 & 185 & $18,756.74$ & 4.69 & 20.34 & 75.24 & -0.248 \\
\hline TaSMP-12 & TraesCS5D02G026500 & 224 & $22,869.26$ & 5.2 & 52.2 & 70.36 & -0.442 \\
\hline TaSMP-13 & TraesCS5D02G395600 & 266 & $27,028.16$ & 5.04 & 38.1 & 79.4 & -0.273 \\
\hline TaSMP-14 & TraesCS5D02G395700 & 185 & $18,795.83$ & 5.12 & 25.34 & 74.76 & -0.258 \\
\hline TaSMP-15 & TraesCS7A02G333100 & 277 & $28,312.94$ & 4.18 & 23.46 & 70.04 & -0.32 \\
\hline TaSMP-16 & TraesCS7B02G244300 & 275 & $28,060.67$ & 4.19 & 22.74 & 69.49 & -0.308 \\
\hline TaSMP-17 & TraesCS7D02G340400 & 275 & $28,179.74$ & 4.19 & 20.55 & 68.76 & -0.349 \\
\hline TaSMP-2 & TraesCS4A02G030700 & 284 & $28,955.83$ & 4.78 & 36.11 & 70 & -0.412 \\
\hline TaSMP-3 & TraesCS4B02G275300 & 272 & $27,037.57$ & 4.65 & 34.14 & 69.89 & -0.355 \\
\hline TaSMP-4 & TraesCS4D02G273900 & 303 & $30,498.73$ & 5.23 & 40.31 & 73.07 & -0.305 \\
\hline TaSMP-5 & TraesCS5A02G021400 & 220 & $22,346.74$ & 5.31 & 50.58 & 71.64 & -0.376 \\
\hline TaSMP-6 & TraesCS5A02G385600 & 266 & $27,030.13$ & 5.06 & 36.78 & 77.56 & -0.306 \\
\hline TaSMP-7 & TraesCS5A02G385700 & 185 & $18,762.78$ & 5.21 & 21.47 & 74.16 & -0.255 \\
\hline TaSMP-8 & TraesCS5B02G018300 & 225 & $22,887.23$ & 5.31 & 52.92 & 70.93 & -0.424 \\
\hline TaSMP-9 & TraesCS5B02G018900 & 224 & $23,131.59$ & 5.17 & 43.42 & 72.1 & -0.45 \\
\hline
\end{tabular}

Note: MW, Molecular weight (Da); pI, Isoelectric point; GRAVY, Grand average of hydropathicity.

The physical and chemical parameters of 121 TaLEA proteins were shown according to the analysis using the ProtParam online tool. The wheat LEA protein has a maximum length of 457 amino acid residues (TaDehydrin-8) and the shortest of 99 amino acid residues (TaLEA3-2), with isoelectric points ( $\mathrm{pI}$ values) ranged from 4.18 (TaSMP-15) to 10.74 (TaDehydrin-28). The molecular weights range from $10.64 \mathrm{kDa}$ (TaLEA3-2) to $43.89 \mathrm{kDa}$ (TaDehydrin-8) with an average of $20.98 \mathrm{kDa}$. Only 16 proteins have a molecular weight $>30 \mathrm{kDa}$. Analysis of the grand average of hydropathicity (GRAVY) index indicated that all TaLEA proteins were hydrophilic, with all of the index $<0$. The lipid index reflects the thermal stability of the protein in Table 1.

The phylogenetic analysis (Figure 1) revealed two major clades of the TaLEA family. The 47 genes of the TaDehydrin group, the LEA5 group, and part of the LEA1 group were clustered in one clade, while the other six groups were clustered in another one. According to the evolutionary relationship, TaSMP is more closely related to LEA6 and LEA2; LEA1 and LEA4 are more closely related. To classify the TaLEA genes into different subfamilies with higher confidence and to better understand their evolutionary relationship, another two phylogenetic trees were constructed with Arabidopsis and Oryza (Figures S1 and S2). It was indicated that the subfamilies classification of $L E A$ genes in wheat is credible. 


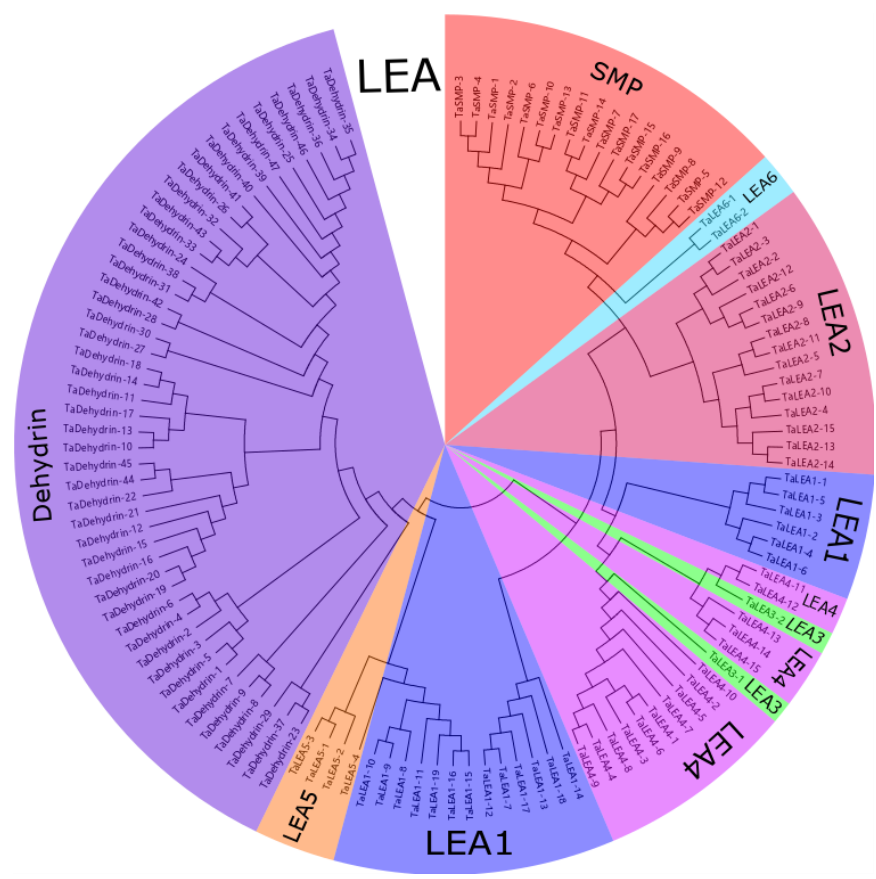

Figure 1. Phylogenetic analysis of wheat Late Embryogenesis-abundant (LEA) proteins. The LEA1, LEA2, LEA3, LEA4, LEA5, LEA6, Dehydrin, and seed maturation protein (SMP) groups are presented in blue, pink, light green, bright purple, orange, light blue, purple, and red, respectively.

\subsection{Structural Characterization of Wheat LEA}

All Gene structure analysis revealed that (Figure 2) wheat LEA genes generally contained few introns, and 24 had no introns. Only two of the 97 intron-containing LEA proteins contained more than one intron. Among the 47 genes of the TaDehydrin group, 46 genes contained only one intron, while the other one (TaDehydrin-21) contained three introns. In the TaLEA1 group, 16 genes had no introns, and the other 3 genes contained only one intron. Among the 15 genes in the TaLEA2 group, 11 were single-intron genes, and the other 4 were intron-free genes. Neither $L E A 3$ nor $L E A 6$ contained introns. There were 14 single-intron genes and 1 double intron gene among the TaLEA4 group. Both of the TaLEA5 and TaSMP groups contained only one intron.

To elucidate the similarity and diversity of protein motifs, the conserved motifs of wheat LEA proteins in each group were analyzed by MEME software. 15 conserved motifs were identified, namely motif1 motif15 (Figure 3). The results indicated that with the exception of the TaLEA3, TaLEA5, and TaLEA6, there were conservative motifs specific to each group (Figure 3). The composition of structural motifs was diverse among different LEA groups, but similar within the same group. Moreover, the motifs encoding LEA domains were relatively conserved, indicating that the functions of TaLEA proteins are intergroup specific. All of the 19 genes in the LEA1 group have motif15, and 12 of them also contain motif13. Among the LEA2 group, 9 members contained 2 motifs and 6 members contained 5 motifs, while each member possessed motif3 and motif4. The TaSMP group contained motif7 and motif10. All LEA4 members had motif13, with 10 of them also having motif11, and 3 of them having motif5 and motif15. There were 27 genes in the Dehydrin group possessing motif1, motif2, motif5, motif6, motif8, and motif9, and all 47 members contained motif1, motif2, and motif5. 

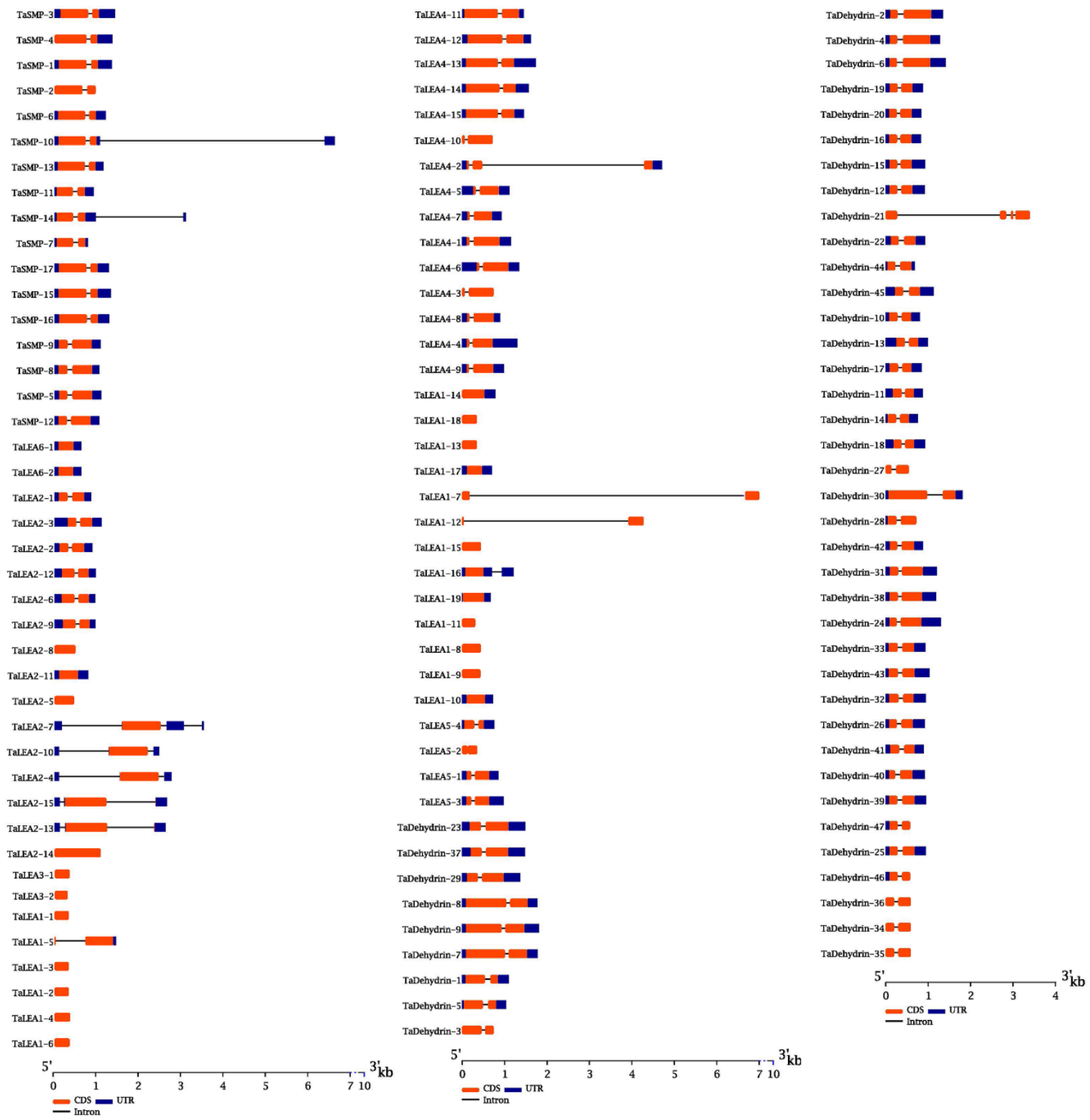

Figure 2. Exon-intron structures of TaLEA genes. Exon-intron are indicated by wide color bar and black line, respectively. 


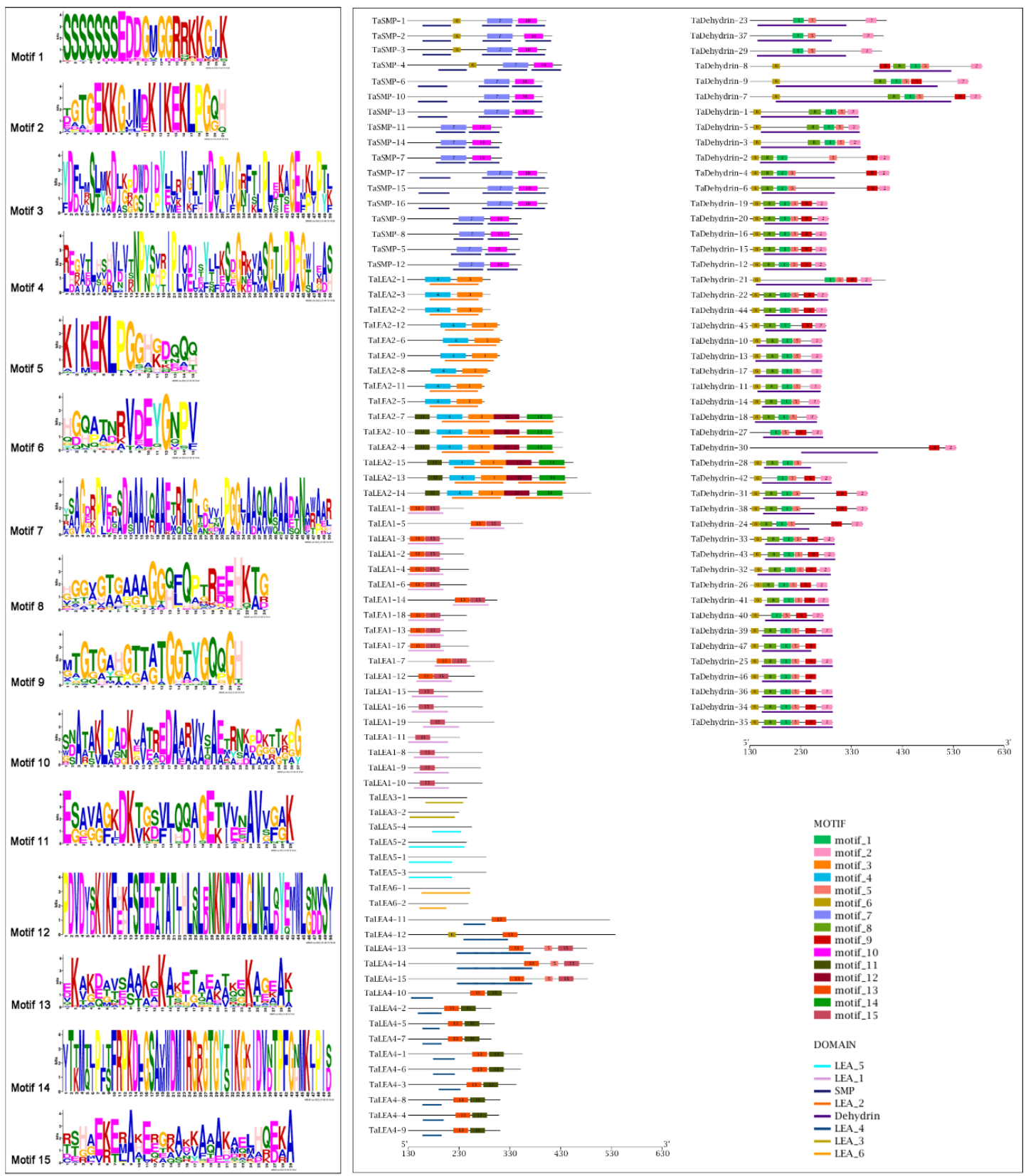

Figure 3. Conserved motifs (left) and their distributions (right) of TaLEA genes predicted by the MEME (Multiple Expectation Maximization for Motif Elicitation) online tool. Each motif is represented by a different colored box with corresponding number. The domain of each subfamily is represented by a different colored thick line below.

\subsection{Chromosomal Locations of Wheat LEA Genes}

Using MapGene2Chrom software to analyze genomic position data, 117 genes were distributed on 21 wheat chromosomes, while the location of the other 4 genes remained unclear (Figure 4). The analysis from the 7 homologous chromosome groups showed that there were 29 LEA genes on the chromosome groups five, representing the most abundant regions, followed by group six with 23 , while the minimum was on chromosome groups two, with only 6 genes. Chromosome groups one and three had 18 and 17 genes, respectively. Chromosome groups four and seven had 12 genes. In total, 37, 40, and 40 TaLEA genes were located on the A, B, and D sub-genome, respectively, which were almost evenly distributed. 

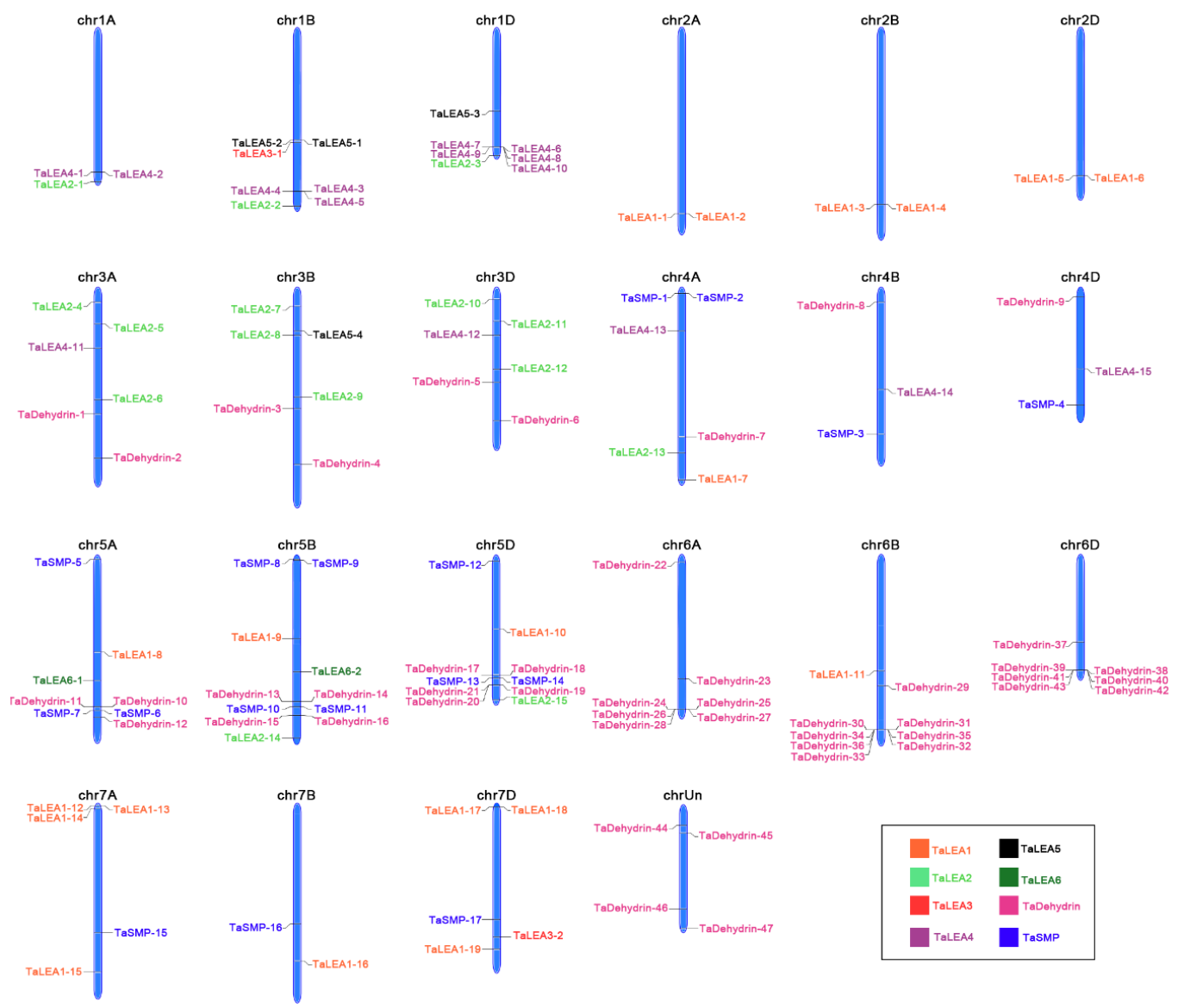

Figure 4. Distribution of TaLEA gene family members on wheat chromosomes. TaLEA1, TaLEA2, TaLEA3, TaLEA4, TaLEA5, TaLEA6, TaDehydrin and TaSMP subfamily are presented in orange, light green, red, purple, black, dark green, pink, and blue.

According to the chromosomal distribution of the TaLEA gene, there were 43 of the Dehydrin group distributed on homologous chromosome groups three, four, five, and six, except for the four genes were still unclear. Among them, there were 7, 8, 7 on chromosome $6 \mathrm{~A}, 6 \mathrm{~B}$, and $6 \mathrm{D}$, and 3, 4, 5 on $5 \mathrm{~A}, 5 \mathrm{~B}$, and $5 \mathrm{D}$, respectively, accounting for $72.34 \%$ of all Dehydrin members. Such a concentrated distribution deserves further study in the future.

\subsection{Expression Profile Analysis of Wheat LEA Genes in Different Tissues}

To gain insight about the expression profile of these identified TaLEA genes, the publicly available RNA-Seq data were collected from the Wheat Expression Browser database. The expression analysis was performed on grains, roots, leaves/shoots, and spikes. A heat map was created according to the $\log _{10}$ (tpm +0.0001$)$ of 121 TaLEA genes (Figure 5). It was indicated that expression patterns of TaLEA genes in different tissues were quite different. 93 genes highly expressed in grains, and among them there were 35 out of 47 members in the Dehydrin subfamily; 17 out of 19 in LEA1; all members of LEA4, LEA5 and LEA6. Whereas, very low expression levels of these 93 genes were observed in the other three tissues, except for 12 in roots and 8 in spikes were also high. 11 highly expressed genes were only observed in spikes, and among them there were 6 members of LEA2 and two members of the LEA3 subfamily. Almost no gene highly expressed in all four tissues and only several genes had higher expression levels in multiple tissues. 


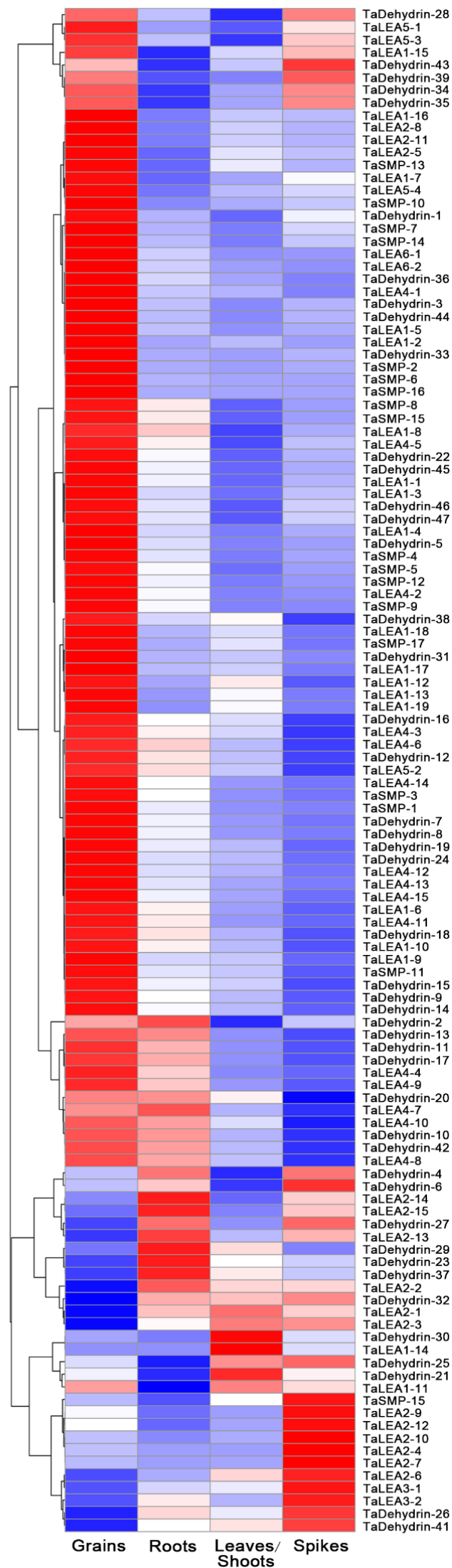

Figure 5. Expression profiling of TaLEA genes in different tissues. RNA-seq date downloaded from Wheat Expression Browser was used to analysis expression pattern. The heat map was drawn in $\log _{10}$ $(\mathrm{tpm}+0.0001)$-transformed expression values. Color scale on the right represent relative expression levels: red represents high level and blue represent low level. 


\section{5. qRT-PCR Analysis of Wheat LEA Genes in the Grain Maturation of Two Different Cultivers}

According to the analysis of gene expression in different tissues, 12 TaLEA genes highly expressed in grains were selected to verify the potential role of TaLEA genes in the maturation of seed. Expression levels at different stages post anthesis of Yangmai16 and Yangmai15 were analyzed by qRT-PCR.

Results showed that the expression of these TaLEA genes have temporal specificity. On the whole, the expression level of TaLEA genes increased from 15 DAA to 35 DAA (Figure 6) in two genotypes. Interestingly, the expression patterns of TaLEA genes in two genotypes presented different characteristics. In Yangmai16, the maximum expression level of 9 genes except TaDehydrin-3, TaLEA5-1 and TaSMP-1 were observed at $30 \mathrm{DAA}$, whereas there were 8 genes in Yangmai 15 with maximum expression level at 35 DAA. For most genes, the peak of expression appeared earlier in Yangmai16. Statistical analysis indicated that, at 25 DAA, the expression level of 8 genes in Yangmai 16 was significantly higher than Yangmai 15.
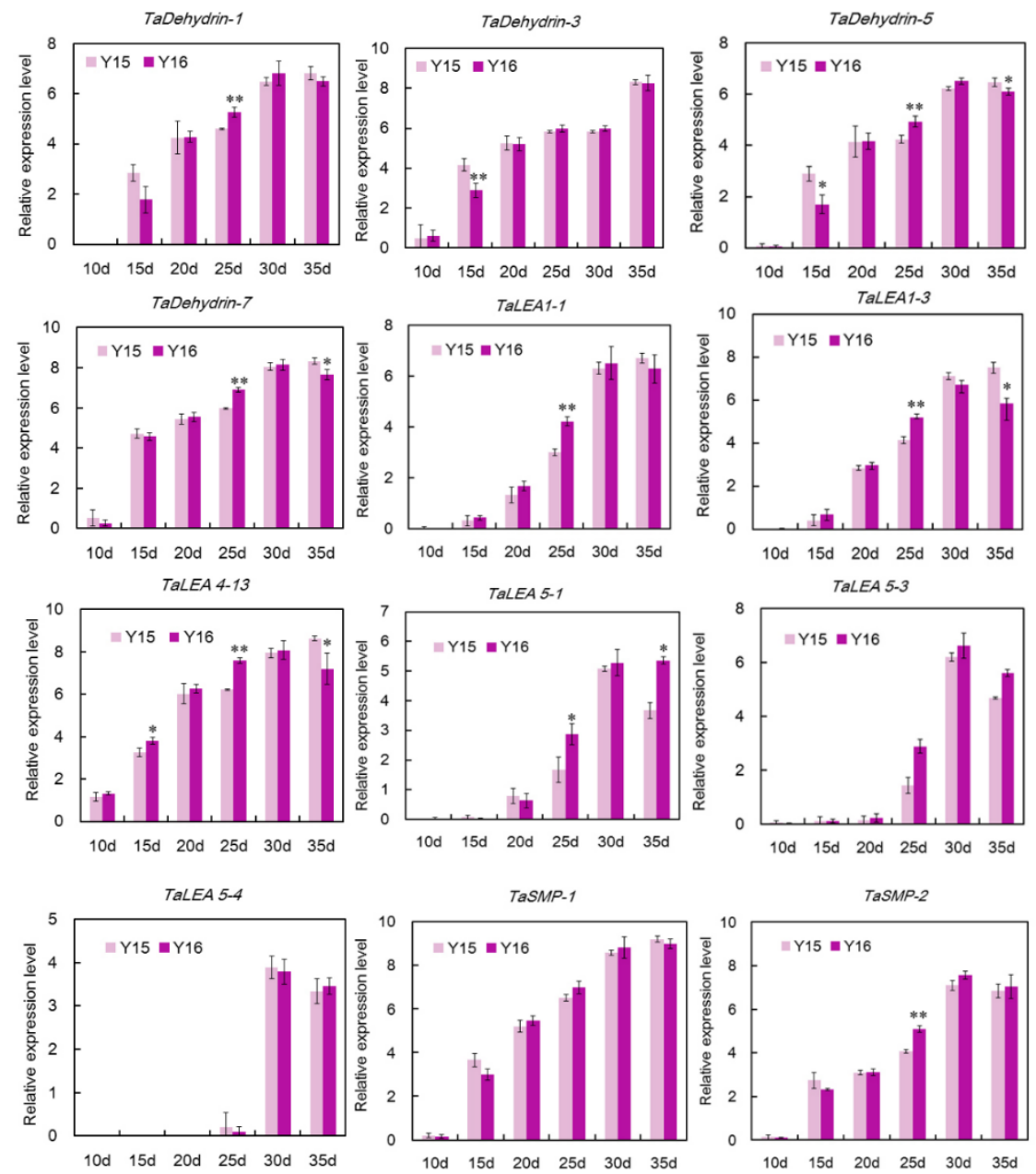

Figure 6. Expression profiles of 12 wheat $L E A$ genes during grain filling and maturation. Purple and light purple columns indicate Yangmai16 and Yangmai 15, respectively. Values represent means \pm standard deviation of three replicates. Asterisks reveal the gene significantly higher or lower in Yangmai 16 than in Yangmai 15 by $t$-test $\left({ }^{*} p<0.05,{ }^{* *} p<0.01\right)$.

According to the determination of phenotypic character of maturation, the increase of grain dry weight in Yangmai16 was faster than that in Yangmai15 (Figure 7A). At 30 DAA, the grain filling of yangmai16 grain was almost completed. Statistical analysis indicated that the average grain filling rate was significantly higher in Yangmai $16(P=0.0185)$. The moisture content curve and the average seed 
dehydration rate indicated that the dehydration of Yangmai 16 was faster $\left(P=1.69 \times 10^{-4}\right)$ and started earlier than Yangmai 15, which could be judged by the appearance and color of the seeds (Figure 7B,C).

A

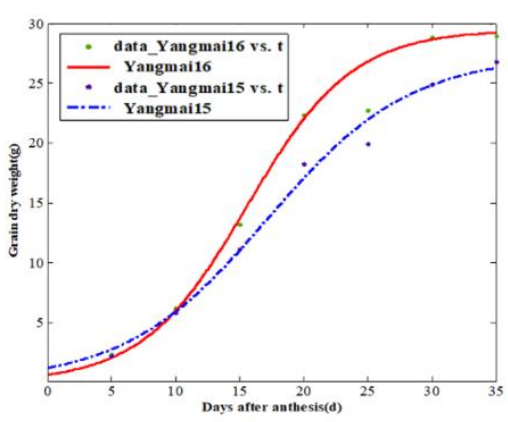

B

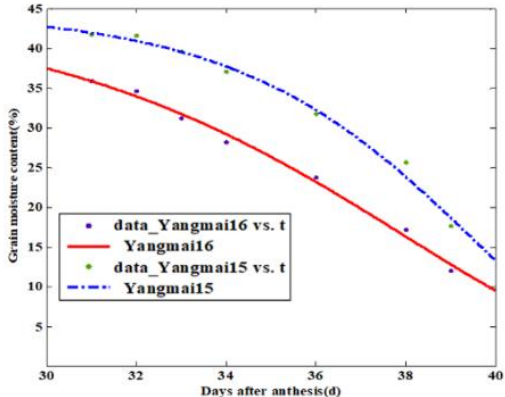

C
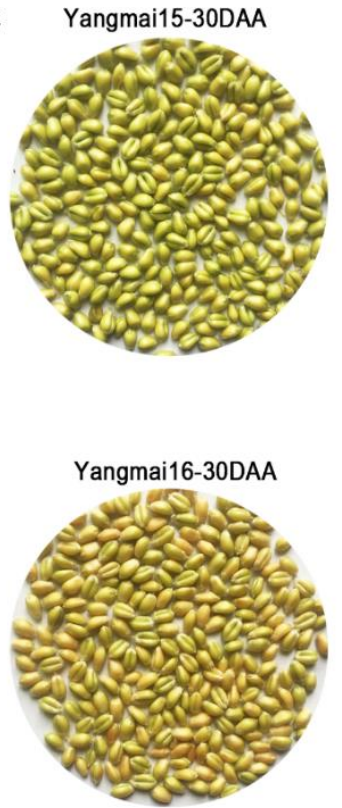
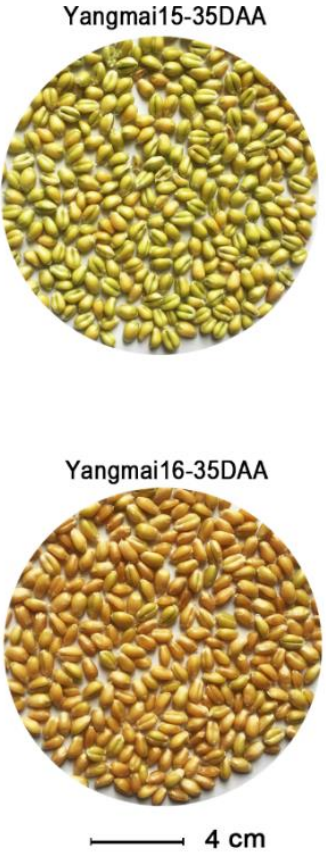

Figure 7. Phenotypic character of grain maturation in Yangmai 15 and Yangmai 16. (A), comparison of grain dry weight. (B), comparison of grain moisture content. (C), appearance of grains during maturation progress; $\mathrm{Bar}=4 \mathrm{~cm}$.

\section{Discussion}

\subsection{Identification and Analysis of Wheat LEA Gene Family}

In this study, 121 wheat $L E A$ homologous were identified by genomic analysis. Wheat LEA family is bigger than rice (34), corn (32), soybean (36), potato (74), Arabidopsis (51), and canola (108), but less than upland cotton (242). We speculated that in the process of hybridization and chromosome doubling by three species, the number of genes had also doubled and finally formed an allohexaploid species with a huge genome [46-48]. It is also possible that most of the wheat LEA genes were retained during subsequent evolution due to genome replication [49]. Functional differentiation of $L E A$ genes during the evolution process could facilitate the regulation of development and adaptation to the environment.

The largest group of the wheat LEA family Dehydrin accounts for about $40 \%$ of the total number of family members. However, the largest group was Dehydrin in rice [15] and LEA3 in soybeans [50]. In plum blossom, the largest groups were Dehydrin and LEA2 [10]. LEA2 group in potato had the most members, accounting for 45 of all 74 LEA genes, while the Dehydrin group had only 5 [13]. The difference above indicated that $L E A$ family genes may have evolved independently after the differentiation of these species.

Gene structure analysis revealed that wheat LEA family genes generally lack introns. For instance, there were 24 genes that don't have introns and 95 genes that have only one intron, while only 2 genes contained more than one intron. The phenomenon was also found in other species [13,50,51]. Perhaps it could be explained by the early intron model of protein-coding gene origin [52]. In general, genes that respond to stress contain fewer introns. Introns can have a deleterious effect on gene expression by delaying transcript production [18]. Moreover, introns can extend the length of the nascent transcript, resulting in an additional expense for transcription [53]. The small number of introns may be a result of adaptation to the environment, which takes less time from transcription to translation, allowing rapid gene expression and functional protein production in response to stresses [53]. DREB [54], 
AP2/ERF [55], and HD-Zip [42], which play important roles in response to diverse stresses, showing similar phenomenon.

The expression profiles of TaLEA family members in different tissues suggested that many TaLEA genes have obvious spatial specificity. However, they were still mainly enriched in the spikes and grains. Our study could be helpful for further investigation of $L E A$ genes with spatiotemporal expression specificity and evaluation of their roles in desiccation tolerance.

\subsection{Wheat Seed Desiccation and the Roles of TaLEA Genes in Acquirement of Desiccation Tolerance}

With the prospect of climate changes that are shaping future agricultural practices, the production of highly vigorous seeds have become a key lever to improve yields and a focus of food security and genetic resources [56]. Because of the long growth duration of common wheat varieties, plants must face various biotic and abiotic stresses in fields, especially during the stage of seed maturity [57]. The stage of seed maturity at harvest, which was also associated with the desiccation tolerance, is a major factor influencing seed vigor and grain quality [58]. Nowadays, faster filling and dehydration of wheat seeds achieved more popularity in China because of the important role for optimizing the new cropping systems.

The wheat seeds undergo three development phases: embryo morphogenesis, material accumulation, and mature dehydration. During the last stage, the metabolism is correspondingly weakened, along with the rapid decrease of water content, which then turn on the transition from morphogenesis to germination [59-61]. Before and during dehydration, physiological and biochemical changes contribute to the acquisition of desiccation tolerance.

The correlation between LEA protein and desiccation tolerance had been confirmed in many orthodox seeds $[62,63]$. In this study, the spatial expression pattern of TaLEA indicated that some genes display high expression levels mainly in spikes and grains. Two spring wheat variety Yangmai16 and Yangmai15 were then used for quantitative verification. The results indicated that Yangmai16 had certain advantages in time and quantity of expression at $25 \mathrm{DAA}$, in which the maximum expression of 8 TaLEA genes appeared earlier than that of Yangmai15. It could be a hint of the inherent genetic differences between two varieties. We speculated that the phenotype of earlier and faster dehydration, which may also possess higher desiccation tolerance theoretically, were correlated with the different expression levels of $L E A$ genes in grains.

The contribution of LEA to maintain seed desiccation tolerance is possibility due to their thermal stability and high hydrophilicity, acting as a dehydration protectant and substitute of water [64]. During the mature dehydration of seeds, the protein of Dehydrins will be present in the cell like a "space filler", maintaining the dissolved character of cell fluid to avoid damage to cell architecture [21]. Magnetic Resonance Imaging (MRI) has been used for tracking and locating the distribution regular of water during seed maturation. It was shown that under the action of Dehydrins, water moves against potential, and the sufficient water in the surroundings of the seed could maintain the available flowing water content in the cells $[65,66]$. LEA were also supposed to regulate the expression of other genes by direct binding, which still lacks evidence.

Four questions that need to be considered were raised by Song and Fu in the last century [67]: What are the signals that induce the mature dehydration during seed development? Are these signals from the seed itself (embryo, storage tissue, and seed coat) or the maternal tissues? What are the acceptors in seeds that response to the dehydration signal? And last but not least, what are the subtle effects of LEA proteins in cells and sub-cells leading to desiccation tolerance? Answers to these questions would be valuable for a better understanding of mature dehydration mechanisms and germplasm conservation, as well as the genetic improvement of crops.

Supplementary Materials: The following are available online at http://www.mdpi.com/2073-4425/10/9/696/s1, Table S1: Primers for qRT-PCR analysis; Figure S1: Phylogenetic analysis of LEA proteins among wheat (121), Arabidopsis (51) and rice (34) (by ML method); Figure S2: Phylogenetic analysis of LEA proteins among wheat (121), Arabidopsis (51) and rice (34) (by MP method). 
Author Contributions: Conceptualization, D.L. and D.G.; methodology, formal analysis, and software, J.S. and G.L.; validation, J.S., J.L. and X.Z.; investigation, D.L., D.Z., C.Z. and H.W.; writing-original draft preparation, D.L. and J.S.; writing-review and editing, D.L. and D.G.; supervision and project administration, D.G.; funding acquisition, D.L. and D.G.

Funding: This research was funded by National Natural Science Foundation of China, grant number 31700163; the National Key Research and Development Program of China, grant number 2017YFD0100800, and Natural Science Foundation of Yangzhou, grant number YZ2017100.

Acknowledgments: We are grateful to Dawei Yan for language improvement of the manuscript.

Conflicts of Interest: The authors declare no conflict of interest. The funders had no role in the design of the study; in the collection, analyses, or interpretation of data; in the writing of the manuscript, or in the decision to publish the results.

\section{References}

1. Dure, L.; Crouch, M.; Harada, J.; Ho, T.H.; Mundy, J.; Quatrano, R.; Thomas, T.; Sung, Z.R. Common amino acid sequence domains among the LEA proteins of higher plants. Plant Mol. Biol. 1989, 12, 475-486. [CrossRef] [PubMed]

2. Olveracarrillo, Y.; Reyes, J.L.; Covarrubias, A.A. Late embryogenesis abundant proteins: Versatile players in the plant adaptation to water limiting environments. Plant Signal. Behav. 2011, 6, 586-589. [CrossRef] [PubMed]

3. Finch-Savage, W.E.; Leubner-Metzger, G. Seed dormancy and the control of germination. New Phytol. 2006, 171, 501-523. [CrossRef] [PubMed]

4. Angelovici, R.; Galili, G.; Fernie, A.R.; Fait, A. Seed desiccation: A bridge between maturation and germination. Trends Plant Sci. 2010, 15, 211-218. [CrossRef] [PubMed]

5. Roberts, E.H. Predicting the storage life of seeds. Seed Sci. Technol. 1973, 1, 499-514.

6. Manz, B.; Muller, K.; Kucera, B.; Volke, F.; Leubnermetzger, G. Water uptake and distribution in germinating tobacco seeds investigated in vivo by nuclear magnetic resonance imaging. Plant Physiol. 2005, 138, 1538-1551. [CrossRef] [PubMed]

7. Dure, L.; Greenway, S.; Galau, G.A. Developmental biochemistry of cottonseed embryogenesis and germination: Changing messenger ribonucleic acid populations as shown by in vitro and in vivo protein synthesis. Biochemistry 1981, 20, 4162-4168. [CrossRef] [PubMed]

8. Ingram, J.; Bartels, D. The molecular basis of dehydration tolerance in plants. Annu. Rev. Plant Physiol. Plant Mol. Biol. 1996, 47, 377-403. [CrossRef] [PubMed]

9. Hundertmark, M.; Hincha, D.K. LEA (Late Embryogenesis Abundant) proteins and their encoding genes in Arabidopsis thaliana. BMC Genom. 2008, 9, 118-128. [CrossRef]

10. Du, D.; Zhang, Q.; Cheng, T.; Pan, H.; Yang, W.; Sun, L. Genome-wide identification and analysis of late embryogenesis abundant (LEA) genes in Prunus mume. Mol. Biol. Rep. 2013, 40, 1937-1946. [CrossRef]

11. Lim, J.; Lim, C.W.; Lee, S.C. The pepper Late Embryogenesis Abundant protein, CaDIL1, positively regulates drought tolerance and ABA signaling. Front. Plant Sci. 2018, 9, 1301. [CrossRef] [PubMed]

12. Wang, W.; Gao, T.; Chen, J.; Yang, J.; Huang, H.; Yu, Y. The late embryogenesis abundant gene family in tea plant (Camellia sinensis): Genome-wide characterization and expression analysis in response to cold and dehydration stress. Plant Physiol. Biochem. 2019, 135, 277-286. [CrossRef] [PubMed]

13. Chen, Y.; Li, C.; Zhang, B.; Yi, J.; Yang, Y.; Kong, C.; Lei, C.; Gong, M. The role of the Late Embryogenesis-Abundant (LEA) protein family in development and the abiotic stress response: A comprehensive expression analysis of potato (Solanum Tuberosum). Genes 2019, 10, 148. [CrossRef] [PubMed]

14. Amara, I.; Odena, A.; De Oliveira, E.; Moreno, A.; Masmoudi, K.; Pages, M.; Goday, A. Insights into maize LEA proteins: From proteomics to functional approaches. Plant Cell Physiol. 2012, 53, 312-329. [CrossRef] [PubMed]

15. Wang, X.; Zhu, H.; Jin, G.; Liu, H.; Wu, W.; Zhu, J. Genome-scale identification and analysis of LEA genes in rice (Oryza sativa L.). Plant Sci. 2007, 172, 414-420. [CrossRef]

16. Cao, J.; Li, X. Identification and phylogenetic analysis of late embryogenesis abundant proteins family in tomato (Solanum lycopersicum). Planta 2015, 241, 757-772. [CrossRef] [PubMed]

17. Ling, H.; Zeng, X.; Guo, S. Functional insights into the late embryogenesis abundant (LEA) protein family from Dendrobium officinale (Orchidaceae) using an Escherichia coli system. Sci. Rep. 2016, 6, 39693. [CrossRef] 
18. Liang, Y.; Xiong, Z.; Zheng, J.; Xu, D.; Zhu, Z.; Xiang, J.; Gan, J.; Raboanatahiry, N.; Yin, Y.; Li, M. Genome-wide identification, structural analysis and new insights into late embryogenesis abundant (LEA) gene family formation pattern in Brassica napus. Sci. Rep. 2016, 6, 24265. [CrossRef]

19. Bojorquez-Velazquez, E.; Barrera-Pacheco, A.; Espitia-Rangel, E.; Herrera-Estrella, A.; Barba de la Rosa, A.P. Protein analysis reveals differential accumulation of late embryogenesis abundant and storage proteins in seeds of wild and cultivated amaranth species. BMC Plant Biol. 2019, 19, 59. [CrossRef]

20. Hand, S.C.; Menze, M.A.; Toner, M.; Boswell, L.C.; Moore, D. LEA proteins during water stress: Not just for plants anymore. Annu. Rev. Physiol. 2011, 73, 115-134. [CrossRef]

21. Battaglia, M.; Olveracarrillo, Y.; Garciarrubio, A.; Campos, F.; Covarrubias, A.A. The enigmatic LEA proteins and other hydrophilins. Plant Physiol. 2008, 148, 6-24. [CrossRef] [PubMed]

22. Hincha, D.K.; Thalhammer, A. LEA proteins: IDPs with versatile functions in cellular dehydration tolerance. Biochem. Soc. Trans. 2012, 40, 1000-1003. [CrossRef] [PubMed]

23. Hunault, G.; Jaspard, E. LEAPdb: A database for the late embryogenesis abundant proteins. BMC Genom. 2010, 11, 221. [CrossRef] [PubMed]

24. Gonzalez, R.M.; Iusem, N.D. Twenty years of research on Asr (ABA-stress-ripening) genes and proteins. Planta 2014, 239, 941-949. [CrossRef] [PubMed]

25. Wetzler, D.E.; Wightman, F.F.; Bucci, H.A.; Rinaldi, J.; Caramelo, J.J.; Iusem, N.D.; Ricardi, M.M. Conformational plasticity of the intrinsically disordered protein ASR1 modulates its function as a drought stress-responsive gene. PLoS ONE 2018, 13, e0202808. [CrossRef]

26. Tunnacliffe, A.; Wise, M.J. The continuing conundrum of the LEA proteins. Naturwissenschaften 2007, 94, 791-812. [CrossRef] [PubMed]

27. Ren, X.; Zhu, C.; Zeng, G. Current research of basic substances related to desiccation tolerance in seeds. Chin. Bull. Bot. 2001, 18, 183-189.

28. Shinde, S.; Nurul Islam, M.; Ng, C.K. Dehydration stress-induced oscillations in LEA protein transcripts involves abscisic acid in the moss, Physcomitrella patens. New Phytol. 2012, 195, 321-328. [CrossRef]

29. Duan, J.; Cai, W. OsLEA3-2, an abiotic stress induced gene of rice plays a key role in salt and drought tolerance. PLoS ONE 2012, 7, e45117. [CrossRef]

30. Liu, Y.; Wang, L.; Xing, X.; Sun, L.; Pan, J.; Kong, X.; Zhang, M.; Li, D. ZmLEA3, a multifunctional group 3 LEA protein from Maize (Zea mays L.), is involved in biotic and abiotic stresses. Plant Cell Physiol. 2013, 54, 944-959. [CrossRef]

31. Wang, M.; Li, P.; Li, C.; Pan, Y.; Jiang, X.; Zhu, D.; Zhao, Q.; Yu, J. SiLEA14, a novel atypical LEA protein, confers abiotic stress resistance in foxtail millet. BMC Plant Biol. 2014, 14, 290. [CrossRef] [PubMed]

32. Sanchez-Garcia, M.; Alvaro, F.; Peremarti, A.; Trevaskis, B.; Martin-Sanchez, J.A.; Royo, C. Breeding effects on dry matter accumulation and partitioning in Spanish bread wheat during the 20th century. Euphytica 2015, 203, 321-336. [CrossRef]

33. Meena, R.P.; Karnam, V.; Tripathi, S.C.; Jha, A.; Sharma, R.K.; Singh, G.P. Irrigation management strategies in wheat for efficient water use in the regions of depleting water resources. Agric. Water Manag. 2019, 214, 38-46. [CrossRef]

34. Gao, D.; Zhang, X.; Kang, J.; Bie, T.; Zhang, B.; Zhang, X.; Cheng, S. Negative effect of late sowing on wheat production in middle and lower reaches of Yangtze river valley and breeding Strategies. J. Triticeae Crops 2014, 34, 279-283. [CrossRef]

35. Wang, H.; Zhu, D.; Wang, J.; Chen, M.; Zhang, X.; Gao, D. Study on the early maturing characteristics of Yangmai 16 under late planting. J. Triticeae Crops 2016, 36, 1657-1666. [CrossRef]

36. Pfeifer, M.; Kugler, K.G.; Sandve, S.R.; Zhan, B.; Rudi, H.; Hvidsten, T.R.; International Wheat Genome Sequencing Consortium; Mayer, K.F.X.; Olsen, O. Genome interplay in the grain transcriptome of hexaploid bread wheat. Science 2014, 345, 1250091. [CrossRef]

37. Appels, R.; Eversole, K.; Stein, N.; Feuillet, C.; Keller, B.; Rogers, J.; Pozniak, C.J.; Choulet, F.; Distelfeld, A.; Poland, J.; et al. Shifting the limits in wheat research and breeding using a fully annotated reference genome. Science 2018, 361, eaar7191. [CrossRef]

38. Alaux, M.; Rogers, J.; Letellier, T.; Flores, R.; Alfama, F.; Pommier, C.; Mohellibi, N.; Durand, S.; Kimmel, E.; Michotey, C.; et al. Linking the international wheat genome sequencing consortium bread wheat reference genome sequence to wheat genetic and phenomic data. Genome Biol. 2018, 19, 111. [CrossRef] 
39. Ramirez-Gonzalez, R.H.; Borrill, P.; Lang, D.; Harrington, S.A.; Brinton, J.; Venturini, L.; Davey, M.; Jacobs, J.; van Ex, F.; Pasha, A.; et al. The transcriptional landscape of polyploid wheat. Science 2018, 361, eaar6089. [CrossRef]

40. Xu, L.; Tang, Y.; Gao, S.; Su, S.; Hong, L.; Wang, W.; Fang, Z.; Li, X.; Ma, J.; Quan, W.; et al. Comprehensive analyses of the annexin gene family in wheat. BMC Genom. 2016, 17, 415. [CrossRef]

41. Qiao, L.; Zhang, X.; Han, X.; Zhang, L.; Li, X.; Zhan, H.; Ma, J.; Luo, P.; Zhang, W.; Cui, L.; et al. A genome-wide analysis of the auxin/indole-3-acetic acid gene family in hexaploid bread wheat (Triticum aestivum L.). Front. Plant Sci. 2015, 6, 770. [CrossRef] [PubMed]

42. Yue, H.; Shu, D.; Wang, M.; Xing, G.; Zhan, H.; Du, X.; Song, W.; Nie, X. Genome-wide identification and expression analysis of the HD-Zip gene family in wheat (Triticum aestivum L.). Genes 2018, 9, 70. [CrossRef] [PubMed]

43. Kumar, S.; Stecher, G.; Tamura, K. MEGA7: Molecular Evolutionary Genetics Analysis version 7.0 for bigger datasets. Mol. Biol. Evol. 2016, 33, 1870-1874. [CrossRef] [PubMed]

44. Huidong, M. Logistic equation and its application. J. Jingsu Agric. Coll. 1983, 4, 53-57. [CrossRef]

45. Seber, G.; Wild, C. Nonlinear Regression. Chaper 7: Growth Model; Wiley: New York, NY, USA, 1989; pp. $325-365$.

46. Schlueter, J.A.; Dixon, P.; Granger, C.; Grant, D.; Clark, L.; Doyle, J.J.; Shoemaker, R.C. Mining EST databases to resolve evolutionary events in major crop species. Genome 2004, 47, 868-876. [CrossRef]

47. Blanc, G.; Barakat, A.; Guyot, R.; Cooke, R.; Delseny, M. Extensive duplication and reshuffling in the Arabidopsis genome. Plant Cell 2000, 12, 1093-1101. [CrossRef] [PubMed]

48. Wang, X.; Shi, X.; Hao, B.; Ge, S.; Luo, J. Duplication and DNA segmental loss in the rice genome: implications for diploidization. New Phytol. 2005, 165, 937-946. [CrossRef]

49. Blanc, G.; Wolfe, K.H. Widespread paleopolyploidy in model plant species inferred from age distributions of duplicate genes. Plant Cell 2004, 16, 1667-1678. [CrossRef]

50. Li, L.; Xu, H.; Yang, X.; Li, Y.; Hu, Y. Genome-wide identification, classification and expression analysis of LEA gene family in soybean. Sci. Agric. Sin. 2011, 44, 3945-3954. [CrossRef]

51. Li, X.; Cao, J. Late Embryogenesis Abundant (LEA) gene family in maize: Identification, evolution, and expression profiles. Plant Mol. Biol. Report. 2016, 34, 15-28. [CrossRef]

52. Zhaxybayeva, O.; Gogarten, J.P. Spliceosomal introns: New insights into their evolution. Curr. Biol. 2003, 13, R764-R766. [CrossRef] [PubMed]

53. Jeffares, D.C.; Penkett, C.J.; Bahler, J. Rapidly regulated genes are intron poor. Trends Genet. 2008, 24, 375-378. [CrossRef] [PubMed]

54. Tian, W.; Guo, Q.; Li, Z.; Ding, N.; Zhang, S.; Wen, S. Genome-wide identification and expression analysis in the heat stress of the DREB transcription factor family in bread wheat (Triticum aestivum L.). J. Triticeae Crops 2018, 38, 1146-1156. [CrossRef]

55. Shu, Y.; Liu, Y.; Zhang, J.; Song, L.; Guo, C. Genome-wide analysis of the AP2/ERF superfamily genes and their responses to abiotic stress in Medicago truncatula. Front. Plant Sci. 2015, 6, 1247. [CrossRef]

56. Leprince, O.; Pellizzaro, A.; Berriri, S.; Buitink, J. Late seed maturation: Drying without dying. J. Exp. Bot. 2016, 68, 827-841. [CrossRef] [PubMed]

57. Wang, Y.; Xu, H.; Zhu, H.; Tao, Y.; Zhang, G.; Zhang, L.; Zhang, C.; Zhang, Z.; Ma, Z. Classification and expression diversification of wheat dehydrin genes. Plant Sci. 2014, 214, 113-120. [CrossRef]

58. Finch-Savage, W.E.; Bassel, G.W. Seed vigour and crop establishment: Extending performance beyond adaptation. J. Exp. Bot. 2016, 67, 567-591. [CrossRef]

59. Nadaud, I.; Girousse, C.; Debiton, C.; Chambon, C.; Bouzidi, M.F.; Martre, P.; Branlard, G. Proteomic and morphological analysis of early stages of wheat grain development. Proteomics 2010, 10, 2901-2910. [CrossRef]

60. Shewry, P.R.; Mitchell, R.A.C.; Tosi, P.; Wan, Y.; Underwood, C.; Lovegrove, A.; Freeman, J.; Toole, G.A.; Mills, E.N.C.; Ward, J.L. An integrated study of grain development of wheat (cv. Hereward). J. Cereal Sci. 2012, 56, 21-30. [CrossRef]

61. Dong, K.; Zhen, S.; Cheng, Z.; Cao, H.; Ge, P.; Yan, Y. Proteomic analysis reveals key proteins and phosphoproteins upon seed germination of wheat (Triticum aestivum L.). Front. Plant Sci. 2015, 6, 1017. [CrossRef]

62. Xiao, B.; Huang, Y.; Tang, N.; Xiong, L. Over-expression of a LEA gene in rice improves drought resistance under the field conditions. Theor. Appl. Genet. 2007, 115, 35-46. [CrossRef] 
63. Xu, D.; Duan, X.; Wang, B.; Hong, B.; Ho, T.; Wu, R. Expression of a late embryogenesis abundant protein gene, HVA1, from barley confers tolerance to water deficit and salt stress in transgenic rice. Plant Physiol. 1996, 110, 249-257. [CrossRef] [PubMed]

64. Olvera-Carrillo, Y.; Campos, F.; Reyes, J.L.; Garciarrubio, A.; Covarrubias, A.A. Functional analysis of the group 4 Late Embryogenesis Abundant proteins reveals their relevance in the adaptive response during water deficit in Arabidopsis. Plant Physiol. 2010, 154, 373-390. [CrossRef]

65. Garnczarska, M.; Zalewski, T.; Kempka, M. Changes in water status and water distribution in maturing lupin seeds studied by MR imaging and NMR spectroscopy. J. Exp. Bot. 2007, 58, 3961-3969. [CrossRef] [PubMed]

66. Garnczarska, M.; Zalewski, T.; Wojtyla, L. A comparative study of water distribution and dehydrin protein localization in maturing pea seeds. J. Plant Physiol. 2008, 165, 1940-1946. [CrossRef] [PubMed]

67. Song, S.; Fu, J. Role of maturation drying in seed development and germination. Chin. Bull. Bot. 1998, 15, 23-32.

(C) 2019 by the authors. Licensee MDPI, Basel, Switzerland. This article is an open access article distributed under the terms and conditions of the Creative Commons Attribution (CC BY) license (http://creativecommons.org/licenses/by/4.0/). 